\title{
PELVIC FLOOR MUSCLE TRAINING USING BIOFEEDBACK THERAPY VERSUS BILATERAL POSTERIOR TIBIAL NERVE STIMULATION FOR TREATMENT OF OBSTRUCTED
}

DEFECATION A RANDOMISED CONTROLLED TRIAL

Walid Galal AbdAlhakeem Al Shazly, Mohamed Hussein Mohamed Sultan,* Fouad Mohamed Fouad Bassyoui Ashoush

Department of Surgery, Department of Experimental and Clinical Surgery, Medical Research Institute,* Faculty of Medicine, Alexandria University

INTRODUCTION
Obstructed defecation syndrome (ODS) is a type of constipation characterized by two or more
of the following symptoms in more than 25 percent of defecation trials: straining, lumpy or
hard stools, urgency, sense of incomplete evacuation, pelvic heaviness and manual maneuvers
to promote defecation.
obstructed defecation is of two basic types: functional and mechanical. The functional type
involves idiopathic megarectum, anismus (pelvic floor dys-synergy), and descending perineal
syndrome, while the mechanical type includes rectocele, enterocele, internal rectal
intussusception and overt rectal prolapse.
An excessive straining is likely to be the "primummovens", causing tissue weakness and organ
descent, and often is due to longterm anxiety, muscle tension and resulting in non-relaxing
puborectalis muscle. The increased straining causes pudendal nerve stretch which may lead to
a pudendal neuropathy which affects the rectal sensations.
ODS has been also defined as an "iceberg syndrome", as the two most frequent lesions, i.e.,
rectocele and rectal internal mucosal prolapse, present in more than $90 \%$ of patients with
ODS, are easily detectable and may be considered "emerging rocks", whereas the "surgical
ship" is likely to "sink" due to the "underwater rocks", i.e., the occult lesions.

\section{AIM OF THE WORK}

The aim of this study is to compare biofeedback-guided pelvic floor exercise therapy (BFT) with bilateral posterior tibial nerve stimulation (bi-PTNS) in treatment of obstructed defecation syndrome (ODS)

As regard: 1-Wexner constipation score. 2- Quality of life score.

\section{SUBJECTS AND METHODS}

\section{PATIENTS:}

60 Patients diagnosed with obstructed defecation syndrome who fulfilled Rome 4 criteria, of functional constipation syndrome referred to General Surgery Departments of Alexandria Main university Hospitals.

METHODS:

Study design:

This study is a prospective randomized clinical trial. An interventional study as it is the most suitable design to achieve the aim of the present study.

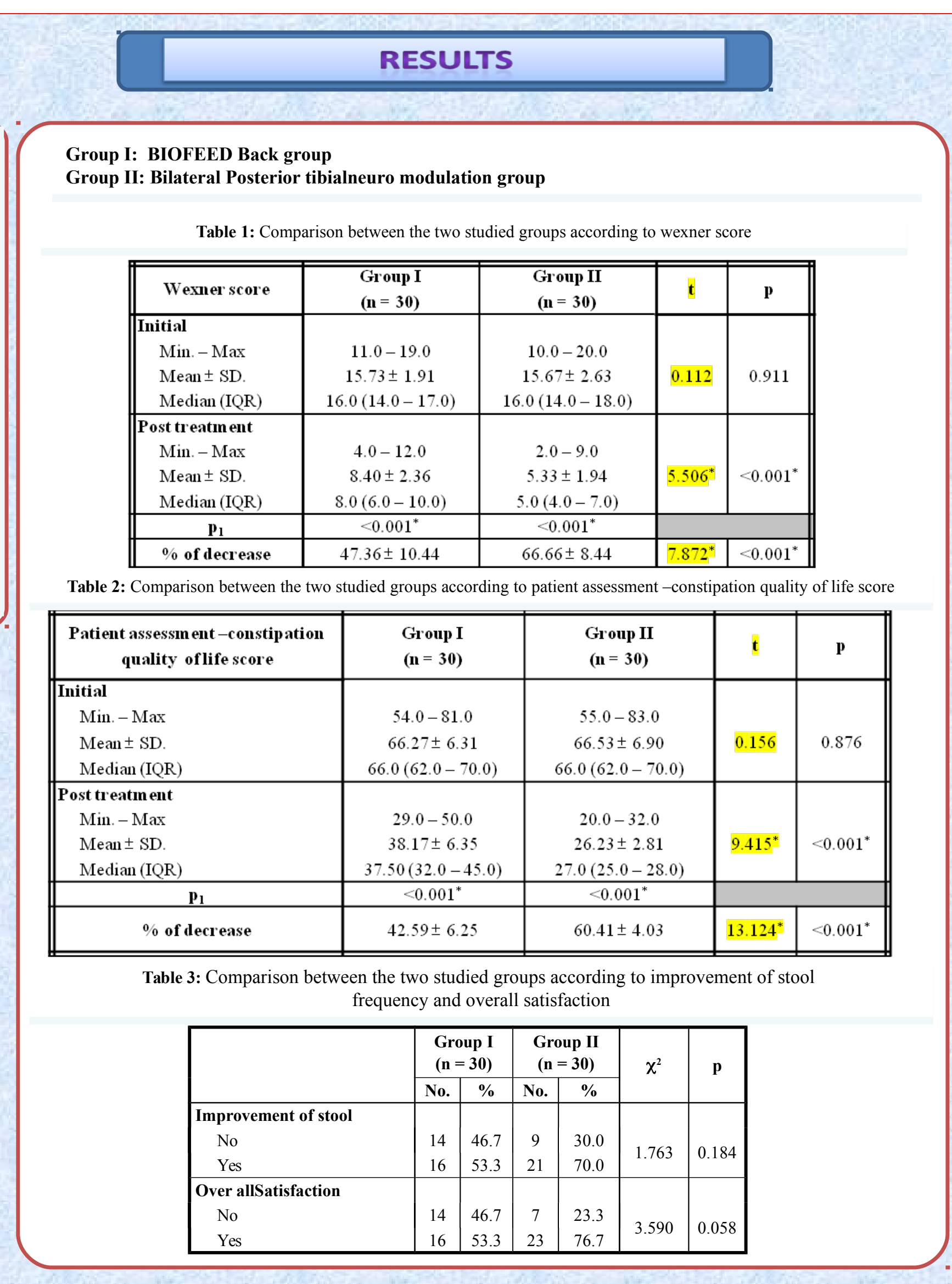

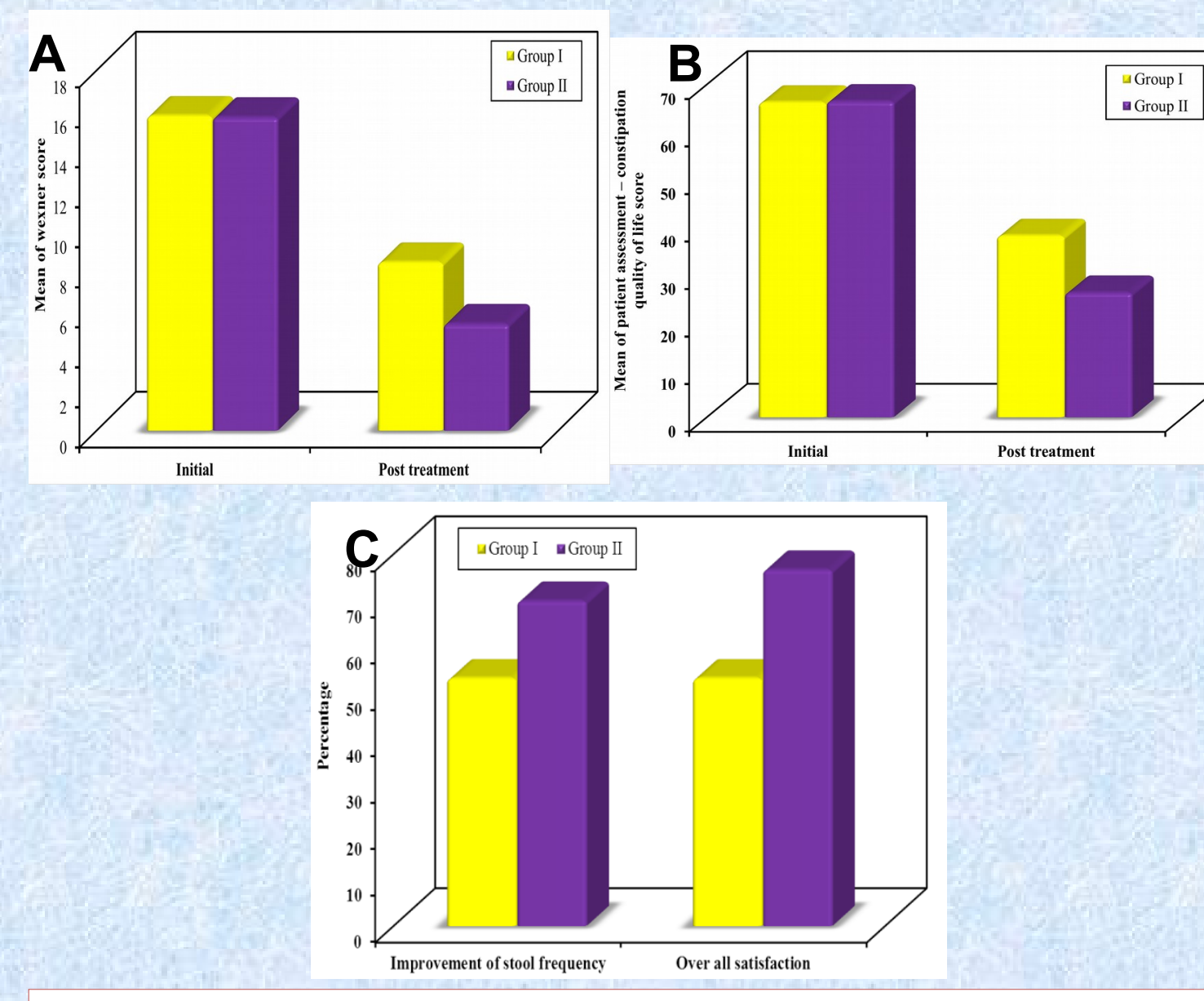

Figure:
A: Comparison between the two studied groups according to Wexner sorer
B: Comparison between the two studied groups according to patient assess

score.
satisfaparison between the two studied groups according to improvement of stool frequency and overall
s.

CONCLUSION

Posterior tibial nerve stimulation is a non-invasive safe procedure which can inprove parents with non-anto a can improve patients with non-anatomic causes of obstructed defecation
and has a great impact on the quality of life of these patients.

$$
\begin{gathered}
\text { 20190Alexandria Faculty of Medicine } \\
\text { CC-BY-NC }
\end{gathered}
$$

